Shivanthan Shanthikumar ORCID iD: 0000-0001-6000-3180

Katherine Frayman ORCID iD: 0000-0003-3479-4470

\title{
Identification of Pediatric Bronchiolitis Obliterans Syndrome Post Hematopoietic Stem Cell Transplantation; Surveillance Is the Key
}

Shivanthan Shanthikumar, FRACP ${ }^{1,2,3}$, Liam Welsh, $\mathrm{PhD}^{1,2}$, Nicole Westrupp, M.S $\mathrm{S}^{1,2}$, Theresa Cole, $\mathrm{PhD}^{3,4}$, Katherine B Frayman, FRACP ${ }^{1,2,3}$, Colin F Robertson, MD ${ }^{1,2,3}$, Sarath C Ranganathan, $\mathrm{PhD}^{1,2,3}$

1. Respiratory and Sleep Medicine, Royal Children's Hospital, Melbourne, Australia

2. Respiratory Diseases, Murdoch Children's Research Institute, Melbourne, Australia

3. Department of Paediatrics, University of Melbourne, Melbourne, Australia 4. Allergy and Immunology, Royal Children's Hospital, Melbourne, Australia

Corresponding Author; Dr Shivanthan Shanthikumar; Respiratory Medicine, Royal Children's Hospital, 50 Flemington Road, Parkville, VIC, 3052, Australia; shivanthan.shanthikumar@rch.org.au

Acknowledgements; The authors have no conflicts of interest to declare Dear Editor,

We read with great interest the article by Walther et $a l^{1}$ regarding long term outcomes of bronchiolitis obliterans syndrome (BOS) in children following haematopoietic stem cell transplantation (HSCT). The authors are to be commended on their study as it is an important contribution to a field where there is a relative paucity of evidence. Given the increasing numbers of HSCT being performed and improved outcomes,

This is the author manuscript accepted for publication and undergone full peer review but has not been through the copyediting, typesetting, pagination and proofreading process, which may lead to differences between this version and the Version of Record. Please cite this article as doi: 10.1002/ppul.25023.

This article is protected by copyright. All rights reserved. 
timely identification and management of pulmonary complications such as BOS is vital.

In particular, the study used multibreath washout to calculate lung clearance index, a more sensitive test for BOS than traditional spirometry. ${ }^{2}$ In addition, the identification of three trajectories for children diagnosed with BOS; rapid persistent decline, persistent obstructive disease with secondary restriction, and resolution, is an important and novel description. This more nuanced understanding of the natural history of BOS in this setting will be an important consideration when designing therapeutic intervention trials. Given there are now ample data showing that around 4.5-8.3\% children post HSCT will develop $\mathrm{BOS}^{3,4}$, based on changes in spirometry, with significant associated morbidity and mortality, well designed intervention trials should be strongly considered.

There are however limitations of Walther et al's study that warrant more detailed discussion, as they limit the applicability of this single centre retrospective chart review to wider clinical practice. The manuscript does not adequately describe the institution's clinical practice regarding evaluation for BOS post-HSCT, although the authors acknowledge a "lack of a standardised follow up protocol for lung function." This is not in keeping with current international practice. International guidelines ${ }^{5-7}$ consistently recommend scheduled lung function surveillance. In addition, in a recent survey of HSCT physicians and pediatric pulmonologists from North America and Australasia, $71.4 \%$ reported that a protocol for monitoring lung function post HSCT existed at their hospital and 53.6\% reported adhering "well” or "very well” to surveillance protocols. ${ }^{8}$ A retrospective review of a centre with a screening program in place showed $75.2 \%$ of patients had a lung function test 12 months post HSCT. ${ }^{3}$ These data indicate that the majority of HSCT centres have a screening protocol in place, and within the limitations of self-reported and single centre data, protocols are adhered too. A potential explanation for the lack of a protocol in the study is that the review period started in 2000, which predates the guidelines. However, if the results are to influence contemporary practice, clinicians must be able to relate the reported findings to current standards of care. In the absence of a standardised follow up protocol, it would be useful if the authors reported the proportion of the 526 eligible patients who underwent lung function assessment, and what triggered a referral for 
testing (i.e. clinical symptoms, graft vs. host disease (GVHD) in another organ). If a high proportion of patients underwent testing then their findings will be more comparable to current international practice, however if only a small proportion underwent testing this is a significant limitation.

The prevalence of BOS in the current study is lower than that reported in the wider literature. We suspect their prevalence is underestimated. The overall GVHD rate (45\%) is higher than might be expected for a cohort that includes nearly 50\% matched sibling donors. ${ }^{9}$, although GVHD grading is not reported. Given the high GVHD rate in this cohort it would be expected that the prevalence of BOS should also be higher or at least in keeping with the literature. The lack of a standardised protocol for screening lung function would likely lead to an underestimation of the prevalence of BOS. It is well established that the early phases of BOS are often asymptomatic and diagnosed based on lung function abnormality. ${ }^{10}$ All 14 BOS cases in this study were symptomatic, suggesting that asymptomatic early cases of BOS cases may have been missed due to lung function not being performed. In particular, this would underestimate BOS cases which follow the resolution trajectory as well as potentially the persistent obstruction trajectory. It also would affect two of the key conclusions of the paper; that BOS incidence is low and that BOS is associated with high mortality.

In summary, the article by Walther et al is a useful contribution to what is an area of growing clinical importance. Strengths of the study include the use of the most sensitive test of small airway function (multibreath washout with calculation of the lung clearance index) and description of three trajectories post BOS diagnosis. However, the lack of a formal surveillance program and likely resultant underestimation of BOS cases is a significant limitation that should be acknowledged before efforts are made to prevent or attenuate lung function decline in BOS

\section{REFERENCES;}

1. Walther S, Rettinger $\mathrm{E}$, Maurer HM, et al. Long-term pulmonary function testing in pediatric bronchiolitis obliterans syndrome after hematopoietic stem cell transplantation. Pediatric pulmonology. 2020, 55(7): 1725-1735.

2. Uhlving $\mathrm{HH}$, Bang $\mathrm{CL}$, Christensen IJ, et al. Lung function after allogeneic hematopoietic stem cell transplantation in children: a longitudinal study in a population-based cohort. Biol Blood Marrow Transplant. 2013;19(9):13481354.

This article is protected by copyright. All rights reserved. 
3. Yoon JS, Chun YH, Lee JW, Chung NG, Cho B. Value of Screening Spirometry for Early Diagnosis of Bronchiolitis Obliterans Syndrome in Children After Allogeneic Hematopoietic Stem Cell Transplantation. Journal of pediatric hematology/oncology. 2015;37(8):e462-467.

4. Duncan CN, Buonanno MR, Barry EV, Myers K, Peritz D, Lehmann L. Bronchiolitis obliterans following pediatric allogeneic hematopoietic stem cell transplantation. Bone Marrow Transplantation. 2008;41(11):971-975.

5. Shenoy S, Gaziev J, Angelucci E, et al. Late Effects Screening Guidelines after Hematopoietic Cell Transplantation (HCT) for Hemoglobinopathy: Consensus Statement from the Second Pediatric Blood and Marrow Transplant Consortium International Conference on Late Effects after Pediatric HCT. Biol Blood Marrow Transplant. 2018;24(7):1313-1321.

6. Chow EJ, Anderson L, Baker KS, et al. Late Effects Surveillance Recommendations among Survivors of Childhood Hematopoietic Cell Transplantation: A Children's Oncology Group Report. Biology of Blood and Marrow Transplantation. 2016;22(5):782-795.

7. Majhail NS, Rizzo JD, Lee SJ, et al. Recommended screening and preventive practices for long-term survivors after hematopoietic cell transplantation. Biol Blood Marrow Transplant. 2012;18(3):348-371.

8. Shanthikumar S, Abts M, Liptzin D, et al. Surveillance for Pulmonary Complications of Pediatric Hemopoetic Stem Cell Transplantation-An International Survey of Current Clinical Practices. In: A52. DIFFUSE LUNG DISEASE, ILD, DRUG INDUCED LUNG DISEASE. American Thoracic Society; 2020:A1983-A1983.

9. Qayed M, Wang T, Hemmer MT, et al. Influence of Age on Acute and Chronic GVHD in Children Undergoing HLA-Identical Sibling Bone Marrow Transplantation for Acute Leukemia: Implications for Prophylaxis. Biol Blood Marrow Transplant. 2018;24(3):521-528.

10. Palmer J, Williams K, Inamoto $\mathrm{Y}$, et al. Pulmonary symptoms measured by the national institutes of health lung score predict overall survival, nonrelapse mortality, and patient-reported outcomes in chronic graft-versus-host disease. Biology of Blood and Marrow Transplantation. 2014;20(3):337-344.

This article is protected by copyright. All rights reserved. 


\section{University Library}

\section{- M M I N E R VA \\ A gateway to Melbourne's research publications}

Minerva Access is the Institutional Repository of The University of Melbourne

Author/s:

Shanthikumar, S;Welsh, L;Westrupp, N;Cole, T;Frayman, KB;Robertson, CF;Ranganathan, SC

Title:

Identification of pediatric bronchiolitis obliterans syndrome posthematopoietic stem cell transplantation; surveillance is the key

Date:

2020-08-20

Citation:

Shanthikumar, S., Welsh, L., Westrupp, N., Cole, T., Frayman, K. B., Robertson, C. F. \& Ranganathan, S. C. (2020). Identification of pediatric bronchiolitis obliterans syndrome posthematopoietic stem cell transplantation; surveillance is the key. PEDIATRIC PULMONOLOGY, 55 (11), pp.2840-2841. https://doi.org/10.1002/ppul.25023.

Persistent Link:

http://hdl.handle.net/11343/276171 